\title{
FEB 141964
}
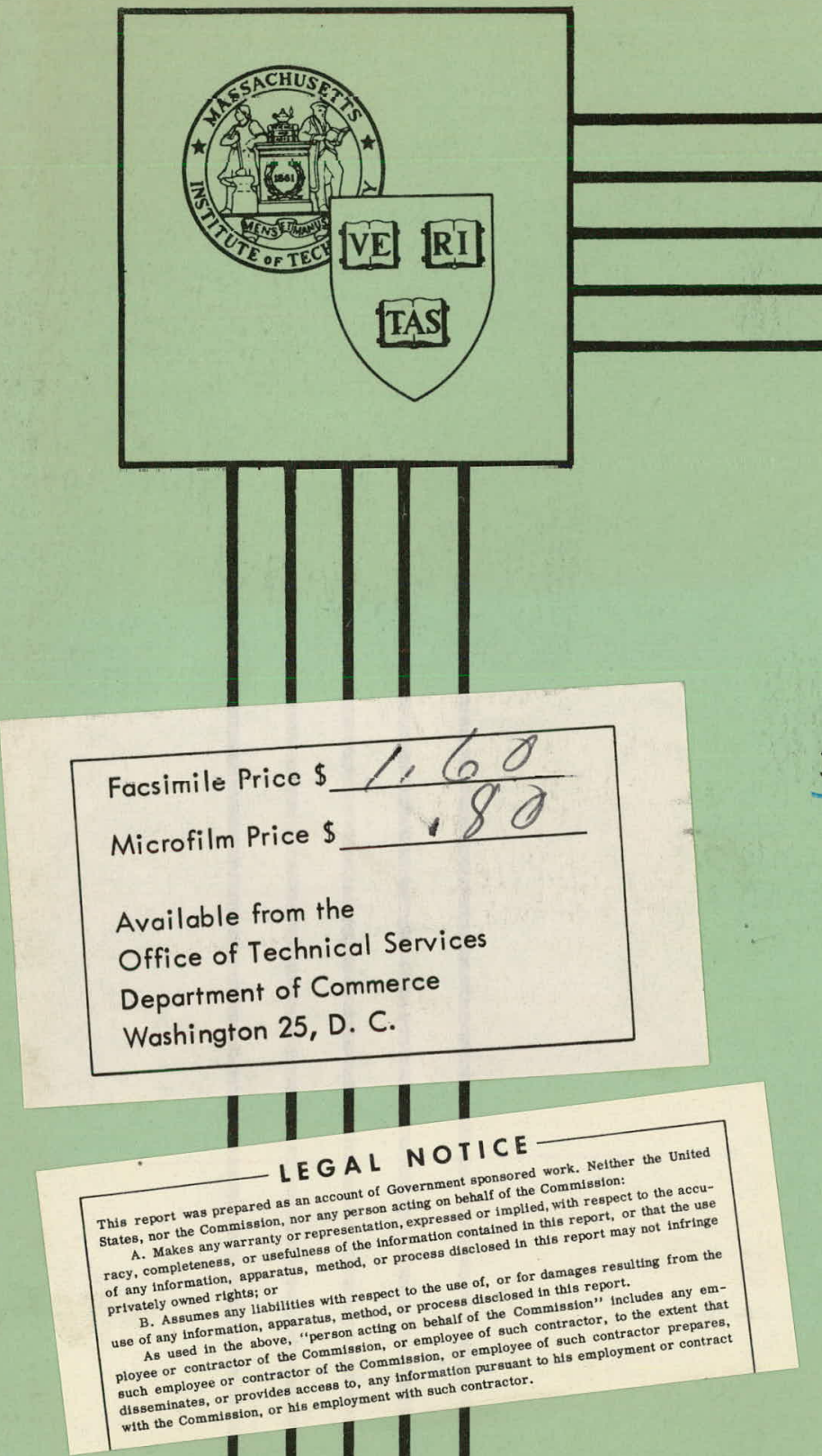

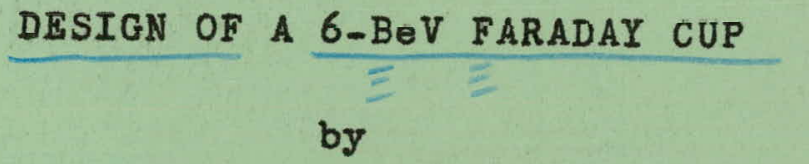

P. H. Burr

January 2, 1964

\section{MASSACHUSETTS INSTITUTE OF TECHNOLOGY and HARVARD UNIVERSITY}

\section{CAMBRIDGE ELECTRON ACCELERATOR}

\author{
CAMBRIDGE 38, MASSACHUSETTS
}




\section{DISCLAIMER}

This report was prepared as an account of work sponsored by an agency of the United States Government. Neither the United States Government nor any agency Thereof, nor any of their employees, makes any warranty, express or implied, or assumes any legal liability or responsibility for the accuracy, completeness, or usefulness of any information, apparatus, product, or process disclosed, or represents that its use would not infringe privately owned rights. Reference herein to any specific commercial product, process, or service by trade name, trademark, manufacturer, or otherwise does not necessarily constitute or imply its endorsement, recommendation, or favoring by the United States Government or any agency thereof. The views and opinions of authors expressed herein do not necessarily state or reflect those of the United States Government or any agency thereof. 


\section{DISCLAIMER}

Portions of this document may be illegible in electronic image products. Images are produced from the best available original document. 
MASSACHUSETTS INSTITUTE OF TECHNOLOGY - HARVARD UNIVERSITY

\section{CAMBRIDGE ELECTRON ACCELERATOR \\ HARVARD UNIVERSITY \\ 42 OXFORD STREET \\ CAMBRIDGE 38, MASS.}

CEAL- 1008

PauI H. Burr

January 2, 1964

\section{DESIGN OF A 6-BeV FARADAY CUP}

\section{ABSTRACT}

This report describes a Faraday cup for use as a direct beam monitor and beam stopper for the 6 Bev external electron beam of the Cambridge Electron Accelerator. Design criteria for an instrument capable of $0.1 \%$ absolute accuracy are presented. 
CEAL-1008

\section{DESIGN OF A 6-Bev FARADAY CUP}

\section{INTRODUCTION}

The external electron beam will be one of the principal facilities of the Cambridge Electron Accelerator; it is described in CEAL-1006 [1]. The faraday cup herein described will be required as an accessory for external electron beam experiments. The function of the cup will be to provide precise primary calibration of the beam in conjunction with secondary monitoring calibration; it may also serve as the beam stopper. It is a "primary standard", in that it will measure directly the quantity of interest - viz, the integrated beam current by transferring the collected charge to a calibrated condenser.

An early proposal for the Faraday cup, presented in report CEA-A-32 [2], suggests an absolute accuracy of $1 \%$, a reproducibility of $0.1 \%$ and an entrance window snout capable of accepting all particles contained in a scattered beam 24 inches in diameter. The 24 inch window was suggested on the assumption that the cup would be permanently installed in a special shielding room in the back wall of the experimental hall [3]. However, as this would necessitate passing the electron beam across the experimental floor, thereby prohibiting access to a considerable floor area during operation, it was suggested that a smaller portable cup be purchased for preliminary experiments. Brown and Tautfest [4], Kretschko, Harder and Pohlit [5] and Isabelle [6] have described Faraday cups extant for energies of $35 \mathrm{Mev}, 40 \mathrm{Mev}, 300 \mathrm{Mev}$ and $1.3 \mathrm{Bev}$, with estimated accuracies ranging from $0.5-1.5 \%$. The CEA Faraday cup incorporates 
many of their design features, with special attention being given to the problem of reducing the sources of parasitic charge. The absolute accuracy is expected to be better than $0.5 \%$. The charge loss or gain at a given electron energy is not expected to change at all, except possibly due to leakage currents, which are easily checked and become obvious during use of the instrument. Reproducibility is therefore expected to be much better than $0.1 \%$.

\section{DESIGN CRITERIA}

Beam absorption is accomplished in the following manner: High energy electrons strike an absorber and are slowed down principally by the emission of photons. The photons thus created make electron-positron pairs, which in turn lose energy. The combination of these processes - Bremsstrahlung and pair production - forms a shower of particles made up of photons, electrons and positrons. As the shower advances axially and radially into the absorber the number of particles increases, and their average energy decreases until it is less than the critical energy of the medium $\left(E_{c} \cong \frac{800}{Z}=6.9 \mathrm{Mev}\right.$ for lead). They will then lose their energy principally by ionization, yeilding low energy products which can only leave the absorber if they are produced near the back or side surfaces. Low energy photons arriving at the back of the block will produce Compton and photo-electrons (this is a source of "parasitic charge" error and will be discussed below). Gamma ray absorption being a statistical phenomenon, a small number of high energy photons may produce electron-positron pairs which 
escape from the absorber; however, as their combined charge is zero, they will not create an error in measurement. Similarly, although the cross section for the effect is small, neutrons having a high escape probability will be produced by the nuclear photo-disintegration of some photons of energy greater than $10 \mathrm{Mev}$ [7]. Having no charge, they will not affect the amount of charge collected by the cup. Other miscellaneous charged particles will be created near the surface, but the cross section for these particles is so extremely small that their combined effect may be considered negligible.

\section{A. Determination of Cylinder Dimensions}

The cylindrical form of the cup is imposed by the axial symmetry of the beam. Cup dimensions are dependent upon the absorber material, incident energy and beam spread. The attenuation of the beam is proportional to the thickness, $x$, measured in radiation lengths $x_{0}$; thus, maximum reduction in dimensions is accomplished by choosing an absorber whose radiation length is small. Because lead posed the problem of melting locally at the point of beam penetration, other materials such as uranium and tungsten were considered. However, they were deemed impractical for reasons of economy, fabrication or induced radioactivity. Lead $\left(x_{0}=5.8 \mathrm{gm} / \mathrm{cm}^{2}\right)$ was chosen as the principal medium, preceded at the entrance face by a small disc of tungsten ( $6 \mathrm{in}$. dia. by 2 in. thick, $x_{0}=6.15 \mathrm{gm} / \mathrm{cm}^{2}$, melting point $=6150^{\circ} \mathrm{F}$ ) to protect the lead at the point of penetration.

Kantz $[8,9]$ has studied electron-induced showers in lead 
CEAL-1008

at $185 \mathrm{Mev}$, summarizing his data in the form of isoenergetic curves giving the depth and radius of a cylinder required to capture a given fraction of the incident electron energy.

Brown and Tautfest [4] have extrapolated his results to higher energies, giving the following expression for the fraction of energy lost by shower penetration, $f_{e}$, as

$$
f_{e}=A e^{-\sigma x}
$$

where $A$ is a constant dependent upon the incident energy, and $\sigma$ is the minimum photon absorption coefficient $\left(\frac{1}{\sigma}=4.24\right.$ radiation lengths). The radius of the absorber, $r$ (radiation lengths), required to effect the greatest capture of radiation for greatest economy is given by

$$
r=0.85 x-2
$$

For lead at $185 \mathrm{Mev}$, eq. (1) becomes

$$
f_{e}=1.75 \exp \left(-\frac{x}{4.25}\right)
$$

Brown and Tautfest further approximate the solution for extension of these data to other energies from the consideration that high energy gammas and electrons are reduced to one half their initial energy in a thickness of log 2 radiation lengths of absorber material. Accordingly, eq. (1) becomes

$$
f_{e}=A_{185} \exp \left[-\sigma\left(x-\log \frac{E_{0}}{185}\right)\right]
$$

provided that

$$
r=0.85 x-2+\frac{i \cdot d}{2} \cdot(r a d . \text { lengths) }
$$

where i.d. is the inside diameter of the mouth of the cup (i.d. $=29.9$ radiation lengths) and $A_{185}$ is equal to 1.75 . 
CEAL-1008

An important parameter for design purposes is the fraction of charged particles escaping from the cup, $f_{p}$. From the study of the isoenergetic curves and an argument given by the above authors [4] the ratio of the number of gamma rays to the number of charged particles escaping from the surface can be derived. Accordingly, the fraction of charged particles lost, $f_{p}$, is related to the fraction of escaping energy, $f_{e}$, by the equation

$$
f_{p}(f \circ r \text { lead }) \cong f_{e}\left(\frac{E_{o}}{85}\right)
$$

Combining eqs. (2) and (4), the fraction of charged particles lost, $f_{p}$, in a lead Faraday cup of $x$ radiation lengths and an in cident electron energy of $E_{0}$ (Mev) is given by

$$
f_{p} \cong 2 E_{0} \exp \left[-\sigma\left(x-\log \frac{E_{0}}{185}\right)\right]
$$

Thus, for $E_{0}=6 \mathrm{Bev}$

$$
\begin{aligned}
& x=3.478-4.25 \log \left(\frac{f}{12000}\right) \text { rad. Iengths } \\
& r=0.85 x-2+\frac{29.9}{2} \quad \text { rad. lengths }
\end{aligned}
$$

Table I gives the minimum dimensions, neglecting sources of parasitic charge, for accuracies of $0.5 \%, 0.1 \%$ and $0.01 \%$.

\begin{tabular}{|l|cc|}
\hline$f_{\mathrm{p}}(\%)$ & Dia. (in.) & Depth (in.) \\
\hline 0.5 & 21 & 9.3 \\
0.1 & 23.3 & 10.7 \\
0.01 & 26.6 & 12.6 \\
\hline
\end{tabular}

TABLE I - Faraday Cup Minimum Dimensions as a Function of Charge Loss, neglecting Sources of Parasitic Charge.

The desired accuracy is $0.5 \%$, but it is known from tests performed with other cups previously mentioned that the above 
prediction may be off by as much as $1 \%$, partly because the error predicted in eq. (5) is an approximation, and partly due to the fact that error due to parasitic charge sources can be several magnitudes greater than error due to shower penetration. To reduce shower penetration error to a negligible amount, an extra 4 - 5 inches of lead was added to the calculated dimensions, giving the cup a depth of 13 inches and a diameter of 27 inches. For these dimensions eq. (5) would predict an error due to shower penetration of less than $0.01 \%$.

This error is further eliminated by the following technique. As stated earlier, low energy photons arriving at the back and side surfaces of the absorber will produce compton electrons and photo-electrons capable of escaping from the mass. The cross section for these effects is much greater in high $z$ materials ( $\sigma_{\text {photoelectric }} \sim z^{5}$, $\sigma_{\text {Compton }} \sim z$ ) [7]. Adding a thickness of light material, in this case aluminum $\left(\mathrm{z}_{\mathrm{Al}}=13\right.$, as compared with $\left.\mathrm{z}_{\mathrm{Pb}}=82\right)$, reduces the cross section by a factor of $10^{4}$ for photo-electric effect, a factor of 6.3 for Compton effect. There will, of course, be a corresponding decrease in the attenuation of the photons, but they are allowed to escape without creating as many charged particles, thus reducing the number of escaping electrons. Isabelle [6] has measured this effect, using $10 \mathrm{~mm}$ of aluminum to cover the back of his lead cylinder, achieving a four-fold reduction in current loss. The CEA Faraday cup was covered with a 0.5 inch skin of aluminum, thus reducing the predicted $0.01 \%$ shower penetration error to $0.0025 \%$. 
CEAL-1008

B. Sources of Parasitic Charge and their Elimination

"Sources of parasitic charge" are those processes other than the shower, capable of producing electrons or positive ions which may be either collected or emitted by the cylinder, thus falsifying the integrated beam current. Figure III shows the general design of the Faraday cup with devices to reduce these effects, as described below.

Backscattering - When the incident beam strikes the front face of the cup some of the electrons are backscattered in such a way that they are lost to measurement. Studies of this phenomenon, done at orsay [6] with lead and $450 \mathrm{Mev}$ incident electrons indicate that $4-5 \%$ of the incident current may be lost due to backscatter. Some of the electrons in the Mer range ( $E<10 \mathrm{Mev}$ ) are due to multiple scattering, but the majority are "knock-ons" of relatively low energy ( $E<500 \mathrm{ev}$ ). Kretschko [10]. has made a study of the energy dependence of backscattered fast electrons for various absorber materials. Extrapolation of his curve for lead indicates that for $6 \mathrm{Bev}$ electrons the percentage of backscattered current is less than $0.1 \%$ of the incident current. Three techniques have been incorporated in the CEA design to eliminate backscatter.

1. The front face of the absorber is covered with 0.5 inches of a low $Z$ material (aluminum) to reduce the cross section for backscatter.

2. The front face of the absorber is covered with an aluminum collector hood (see Fig. III) with a six inch port. The hood is electrically connected to the absorber. A thickness of 0.5 inches of aluminum is sufficient to stop all electrons 
CEAL- 1008

of energy less than 10 Mev. Dimensions were determined from the fraction of electrons in a uniform angular distribution which can escape from the hood, within the cone subtended by the angle $2 \phi$ (see Figs. I and III). Choosing a fractional loss equal to 0.1 and taking an angular distribution per unit solid angle proportional to $\operatorname{Cos} \phi$, the angle $2 \phi$ can be determined from the equation

$$
\frac{\int_{0}^{2 \pi} \int_{0}^{\phi} \cos \phi \sin \phi d \phi d \dot{ }}{\int_{0}^{2 \pi} \int_{0}^{\pi / 2} \cos \phi \sin \phi d \phi d \dot{\alpha}}=0.1
$$

Thus, $2 \phi \cong 38^{\circ}$. This design has an advantage over earlier Faraday cups - which use a re-entrant hole in the absorber itself - in that it decreases the weight of the absorber by approximately 25\%. Using Kretschko's backscattering coefficient of 0.001 for lead and 6 Bev electrons, and the 0.1 fractional loss due to the hood opening, the backscattering error is now reduced to less than $0.01 \%$ of the incident current. 3. A permanent magnet is placed at the entrance face of the cup, with its field perpendicular to the incident beam, to curve the trajectories of backscattered electrons to insure that they will be recaptured. The electrons will be deflected as illustrated in Figure I, with the worst case being the electron emanating from point $P$. The choice of minimum magnetic field, $B_{g}$, will be a function of field depth, $t$, distance to the collecting hood, $d$, and the energy of the electron, $E$. A few of the electronshave energy in the higher range $(500 \mathrm{ev}<\mathrm{E}<10 \mathrm{Mev})$ while most of them are in the low energy 
range $(E<500 \mathrm{ev})$. We take $\mathrm{E}_{\max }$ equal to $1 \mathrm{Mev}$. This electron will have a rigidity $\mathrm{H} \rho=2000$ gauss- inches.

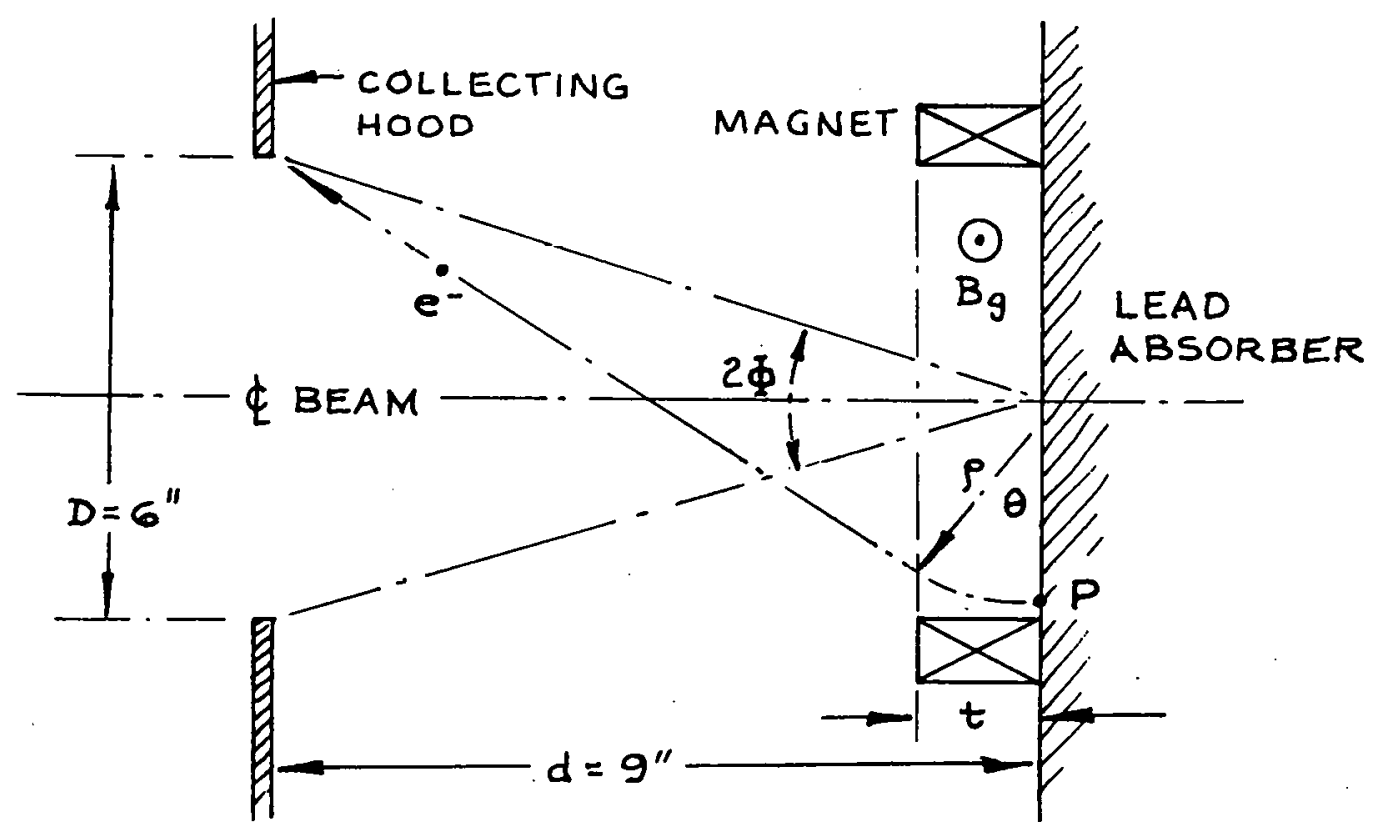

FIGURE I - Determining Minimum $B_{\mathbf{g}}$ for Capture of $1 \mathrm{Mev}$ Backscattered Electrons.

The minimum magnetic field for recapture of I Hev backscattered electrons in the above configuration is expressed by

$$
B_{g}=\frac{\left(B_{g} \rho\right)}{t} \sin \left(\operatorname{Tan}^{-1} \frac{D}{d}\right)
$$

for I Mev, $B_{g} \rho=2000$ gauss-inches; thus

$$
B_{g} t=1110 \text { gauss-inches }
$$

The magnet, shown in Figure IT, is composed of two semicircular Alnico $V$ modules and two carbon steel keepers retained in a hoop, with like poles opposed. This configuration produces a uniform magnetic field, $B_{g}$, within the volume bounded by the magnet. The fringing field outside this volume will continue to deflect the backscattered electrons somewhat further 
than the following calculation would indicate, and thus may be safely ignored.

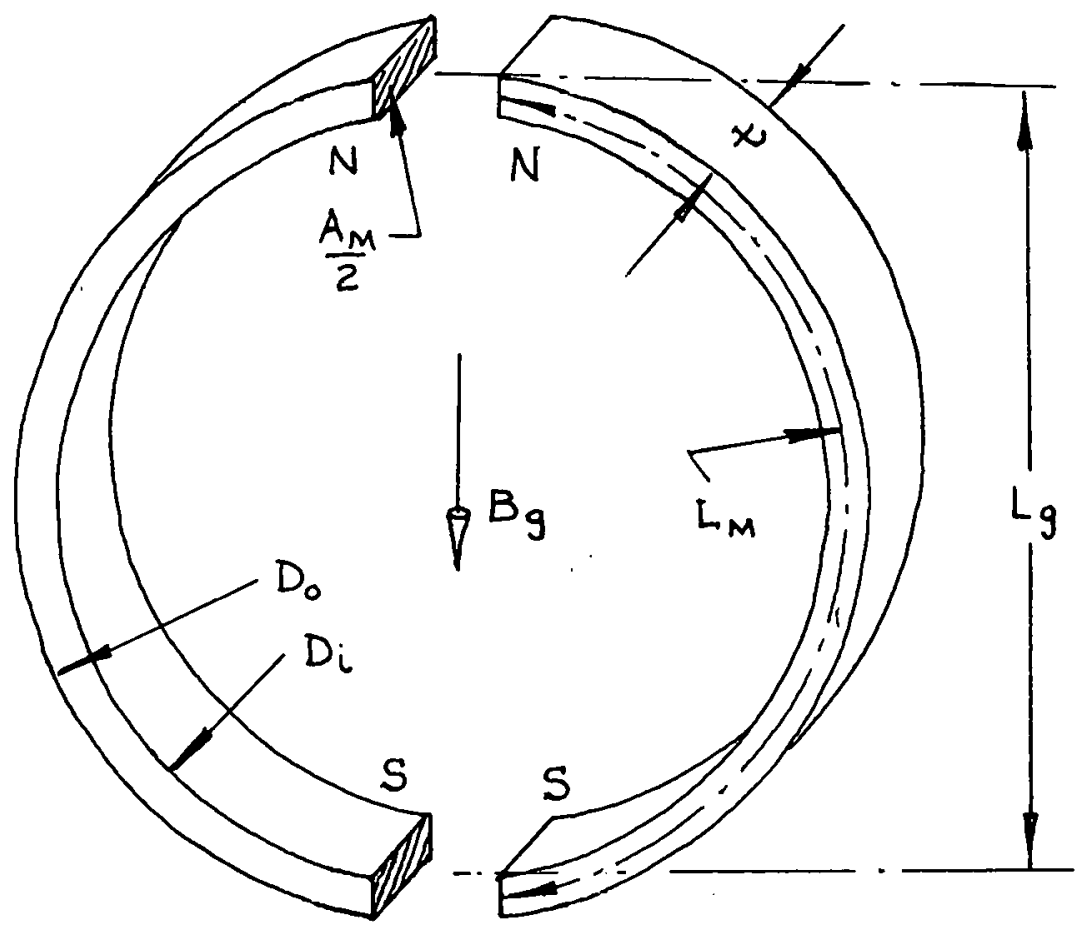

\section{FIGURE II - Alnico V Ring Magnet}

The length, $L_{m}$, of a magnet necessary to produce a flux density, $B_{g}$, in a gap length, $L_{g}$, is related to the H-coordinate of the magnet's operating point, $H_{d}$, by the equation

$$
\mathrm{H}_{\mathrm{d}}=\frac{\mathrm{r}_{f} \mathrm{~B}_{g} \mathrm{~L}_{g}}{\mu \mathrm{L}_{\mathrm{m}}}
$$

where $\mu$ is the permeability (equal to unity in a vacuum) and $r_{f}$ is the reluctance factor, which for the given conditions is assumed to be $1.5[11]$.

From eq. (7), if we choose a field of 350 gauss for 1 Mev electrons, $t \cong 3.25$ inches. Then, assuming a radial wall thickness $1 / 2\left(D_{0}-D_{i}\right)=0.5$ inches, $L_{m} \cong 10.2$ inches. Then, 
from eq. (8), $\mathrm{H}_{\mathrm{d}}=334$. The typical demagnetization and energy product curve for Alnico $V$ [11] gives for this value of $\mathrm{H}_{\mathrm{d}}$ a permeance coefficient, $P$, of 35. To have some safety margin, however, $P$ was assumed to be 25. Figure $V$ shows a curve relating permeance coefficient to dimension ratio, $\mathrm{L} / \mathrm{d}$, for bar magnets of Alnico $V$ in designs where no other material is used. A coefficient of 25 corresponds to an $\mathrm{L} / \mathrm{d}$ ratio of 5.1. The magnet's equivalent area, $A_{m}$, is related to the $\mathrm{L} / \mathrm{d}$ ratio by the equation

$$
A_{m}=\pi\left[\frac{L_{m}}{2\left(\frac{L}{d}\right)}\right]^{2}
$$

Thus, the magnet area, $A_{m}$, must be close to 3.25 square inches. The magnet was built to the above dimensions. It was checked with a rotating coil gauss meter which indicated excellent uniformity, the magnetic field in question varying from 350 to 400 gauss. This magnetic field, in conjunction with the hood and aluminum entrance face, should be sufficient to completely eliminate error due to backscatter.

Ionization - If the Faraday cup were exposed to air, the air would be ionized by the electron beam - the ions thus produced causing an error in measurement. This error is eliminated by enclosing the cup in a vacuum. A pressure of $10^{-5} \mathrm{~mm} \mathrm{Hg}$ will insure that less than $0.005 \%$ of the collected charge will be neutralized by positive ions produced across $40 \mathrm{~cm}$. of evacuated beam path.

The system employed to produce the vacuum consists of a fore pump, cold trap and vacion pump. The vacion pump was 
chosen because it is the most maintenance-free system. After pump-down the mechanical pump and cold trap can be valved off; the system will continue pumping as long as electrical power is on; should power fail, the system will remain under vacuum for a considerable length of time. It is anticipated that the pump may produce a considerable number of troublesome ions which might tend to wander into the region of the cup. To prevent this, a chevron baffle has been positioned at the throat of the pump. Directly below the baffle, provision has been made for the installation of a biased screen to work in conjunction with the baffle, should this prove necessary. The system has been designed to maintain a vacuum in excess of $10^{-6} \mathrm{~mm} \mathrm{Hg}$ for a considerable length of time after shutting off the pump; as this would also interrupt the flow of ions from the pump it will be a simple matter to check the efficiency of the baffle during initial testing of the Faraday cup. As previously mentioned, the lead cup is completely enclosed in a half-inch thick skin of aluminum. The cup is formed by pouring lead into this shell and sealing it off with a welded cap. The seams of the shell are vacuum tight; thus, outgassing of the lead will not present a problem in the attainment of a high vacuum. All vacuum seals are made with indium; organic materials were excluded from the design as they are subject to outgassing and radiation damage.

Secondary Flectrons - Placing the cup in a vacuum necessitates the provision of a thin foil window to allow the beam to enter the vacuum enclosure. As the beam penetrates this foil it will 
produce secondary electrons at the inner foil surface - another source of measurement error. A permanent magnet having the same parameters as the one described above is placed behind the window to curve the trajectories of the secondary electrons such that they will strike the wall of the vacuum chamber. The magnetic field is strong enough to collect all charged particles of energy less than $400 \mathrm{Kev}$. It is believed that almost all of the secondary electrons in question will have energies several magnitudes below $400 \mathrm{Kev}$, most of them being in the ev range. Mounting has been provided at the exit side of the magnet for a biased screen to determine the amount of secondary current with the magnet in place or with the magnet removed.

Leakage Current - The Faraday cup must be electrically isolated from the grounded vacuum enclosure. Four pedestal insulators support the cup and a standoff insulator mounted on the base of the vacuum enclosure provides feed-through for the lead to the current integrator.

With a design limit of $0.01 \%$ error due to leakage current and anticipated beam currents as 10 w as $10^{-9}$ amperes, the maximum allowable leakage is $10^{-13}$ amperes. The potential between cup and ground due to charge accumulated on the integrating condenser (see Fig. IV) is approximately 10 millivolts, necessitating an insulation resistance of only $10^{11}$ ohms. This low voltage of 10 millivolts stems from the nature of the feedback integrating circuit used to measure the charge. However, the problem of leakage currents may become much more 
serious when the cup is biased to several kilovolts.

The pedestal and standoff insulators are made from high alumina ceramic having a volume resistivity of $10^{14} \mathrm{ohms} / \mathrm{cm}^{3}$. The fluted surfaces are glazed with a sodium-potassium-alumina silicate having a clean surface resistivity of about $10^{14} \mathrm{ohms} / \mathrm{cm}^{2}$. Two fluted sections are stacked with a metal guard ring separating them and with kovar fittings mounted at each end; the entire assembly is furnaced brazed with ceramicto-metal, vacuum tight seals.

The metal guard ring at the center of the insulators serves two functions: (a) it can be used to measure the actual amount of leakage current, and (b) when the cup is biased, the biasing voltage can be applied to both the cup and the guard ring, cancelling the potential across the top half of the insulator. The total clean surface resistance of the insulation is approximately $2 \times 10^{12}$ ohms.

C. Construction

The 6 Bev Faraday cup described in this report was built in accordance with the following C. E. A, drawings:

$\begin{array}{ll}\text { E-1614-A } & \text { General Assembly } \\ \text { D-1601-A } & \text { Faraday Cup-Sub-assembly } \\ \text { B-1602-A } & \text { Standoff Insulator } \\ \text { A-1603-A } & \text { Tungsten Heat Plug } \\ \text { B-1604-A } & \text { Lifting Insert } \\ \text { A-1605-A } & \text { Adapter - Sprue and Riser } \\ \text { A-1606-A } & \text { Plug - Sprue and Riser } \\ \text { D-1607-A } & \text { Hood- Sub-Assembly } \\ \text { C-1608-A } & \text { Terminal Flange } \\ \text { D-1609-A } & \text { Vacuum Pump Adapter } \\ \text { C-1610-A } & \text { Chevron Baffle } \\ \text { D-1611-A } & \text { Base } \\ \text { A-1612-A } & \text { Walrus Tooth } \\ \text { D-1613-A } & \text { Fore Pump Vacuum Line } \\ \text { B-1556-A } & \text { Ring Magnet for Electron Recapture } \\ \text { D-1618-A } & \text { Portable Support Table }\end{array}$




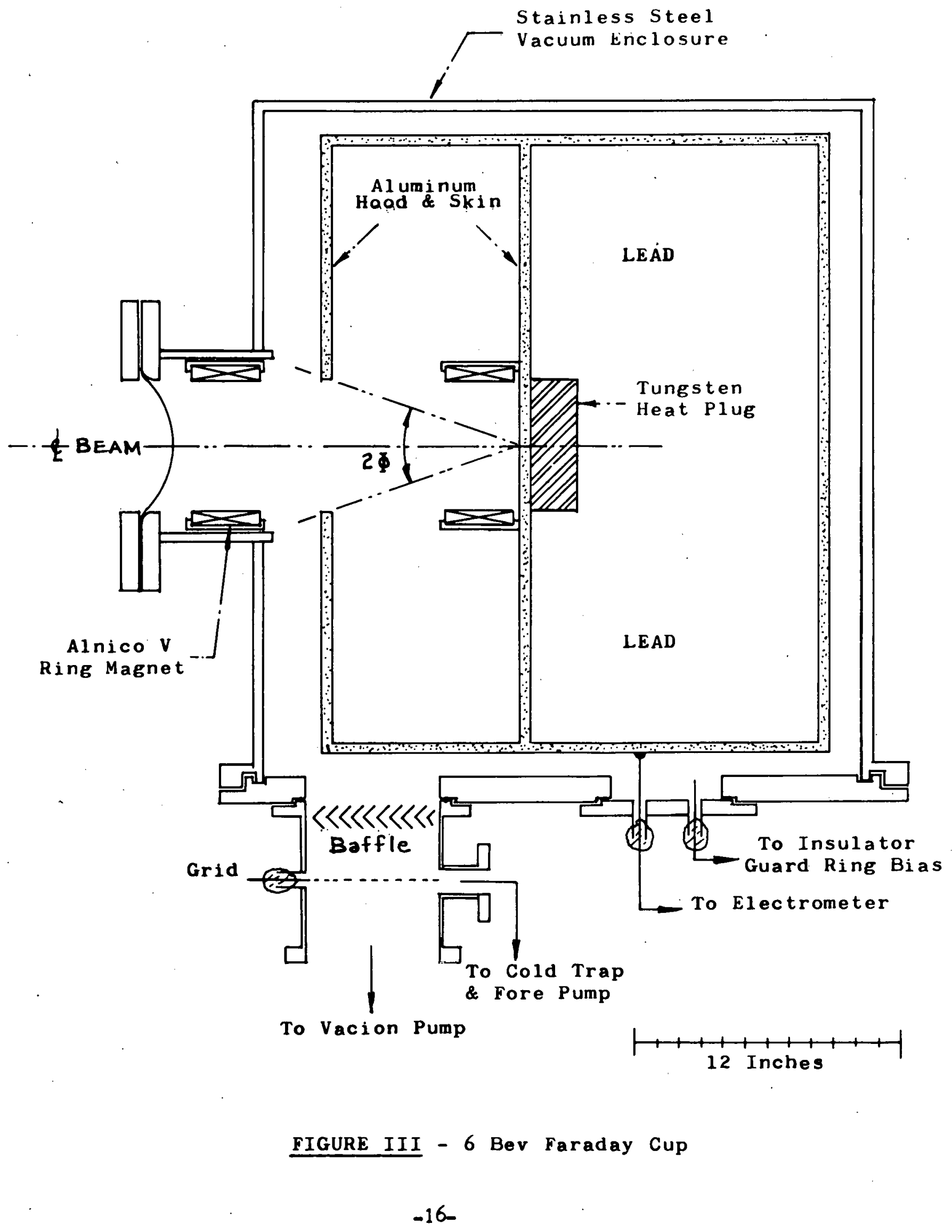




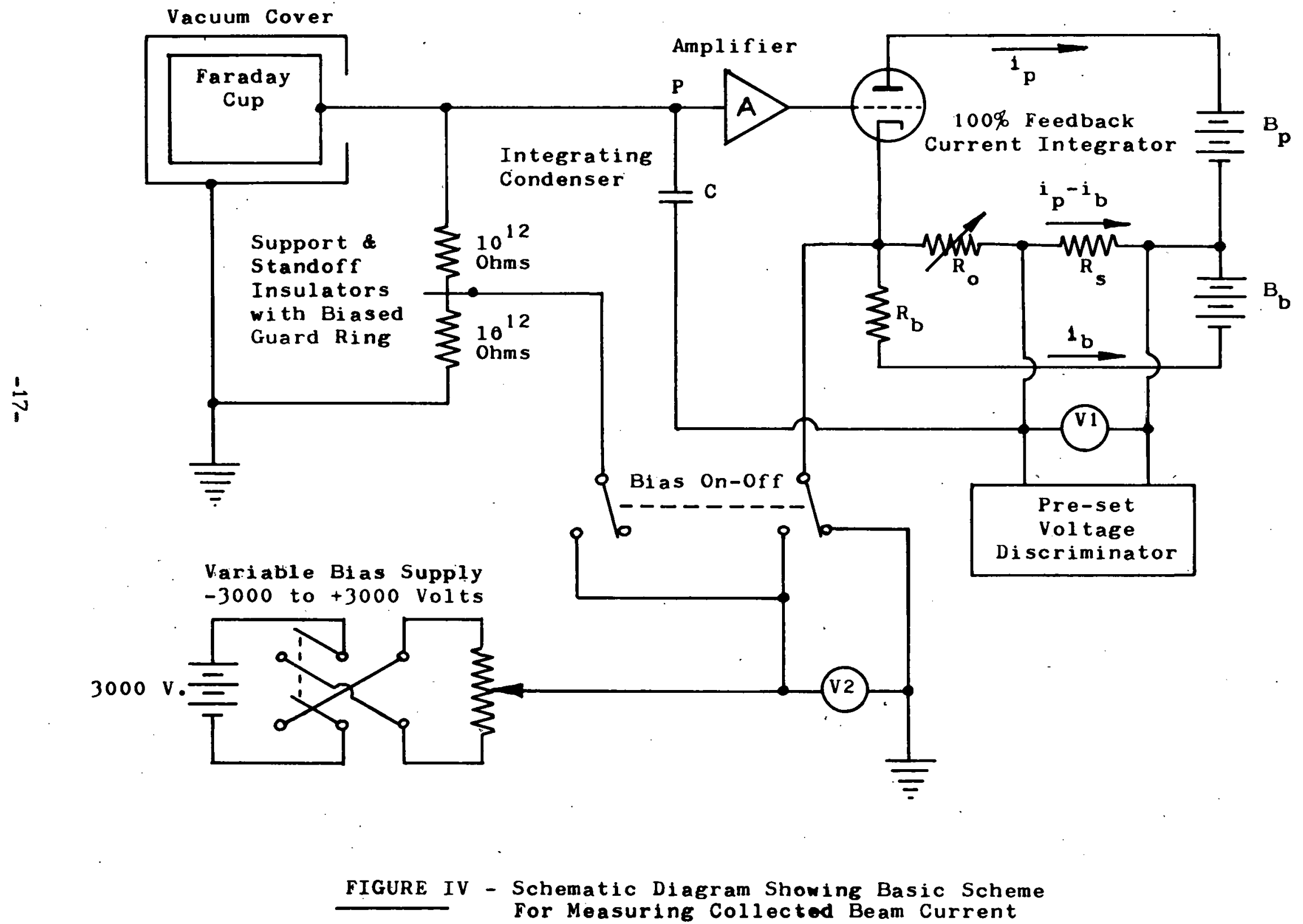




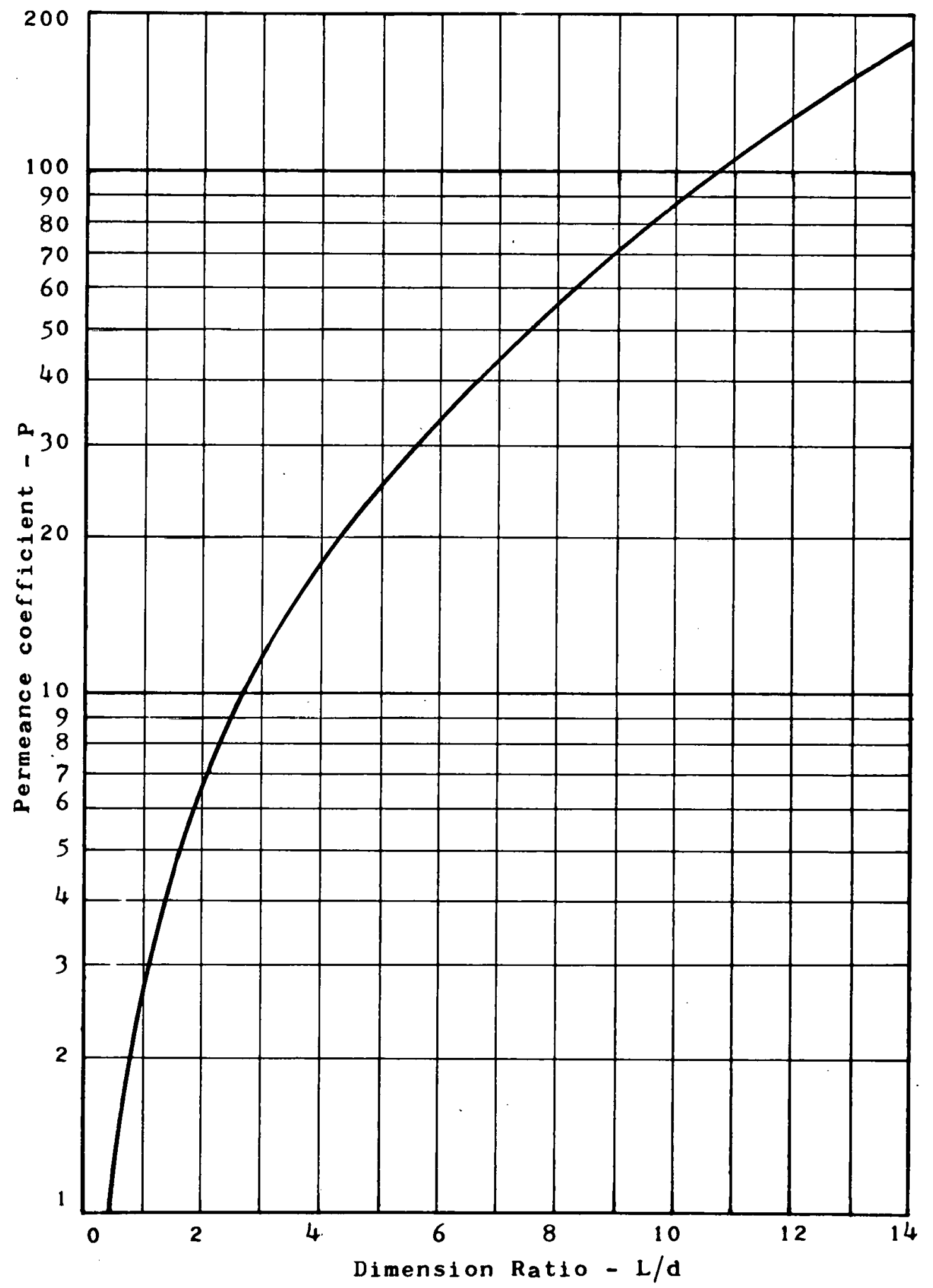

FIGURE $V$ - Permeance Coefficient vs. Dimension Ratio for bar magnets of Alnico $V$. *

* Reproduced from Indiana Permanent Magnet Manual 6A, courtesy of the Indiana Steel Products Division of the Indiana General Corporation, Valparaiso, Indiana, by permission. 


\section{REFERENCES}

1. Brasse, Fischer, Fotino and Robinson, CEAL-1006 (1963).

2. F. Pipkin, N. Ramsey, R. Wilson et al., CEA-A-32 (1962).

3. Charles T. Main, Inc., Boston, Mass., Proposed Electron Beam Trap for the C.E.A., Job No. 2902-1320-1 (1963).

4. K. L. Brown and G. W. Tautfest, Rev. Sci. Inst., 27, No. 9, $696(1956)$.

5. J. Kretschko, D. Harder and W. Pohlit, Nucl. Inst. and Methods, 16, 29 (1962).

6. D. Isabelle, L'Onde Electrique, No. 42I (1962).

7. J. M. Cork, Amer. Institute of Physics Handbook, McGrawHill, $8 f-5$ (1957).

8. A. D. Kantz and R. Hofstadter, Phys. Rev., 89, 3 (1956).

9. R. Hofstadter and A. D. Kantz, Nucleonics, 12, No. 3, $36(1954)$.

10. J. Kretschko, Energy Dependence of the Backscattering of Fast Electrons for Various Absorber Materials, Ph.D. Thesis, Max Planck-Institut für Biophysik (unpublished).

11. Indiana Permanent Magnet Manual 6A, Indiana steel Products Division, Indiana General Corporation, Valparaiso, Ind. 
This report was prepared as an account of Government sponsored work. Neither the United States, nor the Commission, nor any person acting on behalf of the Commission:

A. Makes any warranty or representation, express or implied, with respect to the accuracy, completeness, or usefu1ness of the information contained in this report, or that the use of any information, apparatus, method, or process disclosed in this report may not infringe privately owned rights or

B. Assumes any 1 iabilities with respect to the use of, or for damages resulting from the use of any information, apparatus, method, or process disclosed in this report.

As used in the above, "person acting on behalf of the Commission" includes any employee or contractor of the Commission to the extent that such employee or contractor prepares, handles or distributes, or provides access to any information pursuant to this employment or contract with the commission. 